\title{
EVASÃO E AVALIAÇÃO INSTITUCIONAL NO ENSINO SUPERIOR: UMA DISCUSSÃO BIBLIOGRÁFICA
}

\author{
Cristiane Aparecida dos Santos BagGi* \\ Doraci Alves Lopes**
}

Recebido: mar. 2010

Aprovado: ago. 2010

\footnotetext{
* Mestrado em Educação, aluna do Programa de Pós Graduação PUC, Campinas, SP, Brasil. E-mail: baggi@ puc-campinas.edu.br

** Doutora, professora do Programa de Pós Graduação PUC, Campinas, SP, Brasil. E-mail: doraci@puccampinas.edu.br
}

Resumo: A evasão escolar no ensino superior é um fenômeno complexo e, portanto, não pode ser analisado fora de um contexto histórico mais amplo, pois é reflexo da realidade de níveis anteriores de ensino, influenciando de diversas maneiras para o abandono de um curso superior. A avaliação institucional permeia todos esses processos e pode auxiliar na identificação dos sinais da evasão, reduzindo-a ou mesmo evitando-a. Este artigo analisa a produção teórica que aborda a evasão e a sua relação com a avaliação a partir da Biblioteca Digital de Teses e Dissertações (BDTD) entre 2008-2009. A metodologia baseia-se na pesquisa bibliográfica, denominada estado da arte ou estado do conhecimento, que contribui para a discussão e o mapeamento da produção acadêmica tanto em termos de análise qualitativa, quanto quantitativa. Vimos que a relação entre evasão e avaliação ainda é pouco estudada, sendo mais restrita ainda que a reflexão sobre a evasão no ensino superior.

Palavras-chave: Evasão escolar; Ensino superior; Avaliação institucional.

\section{DROPOUT RATES AND INSTITUTIONAL EVALUATION IN HIGHER EDUCATION: A BIBLIOGRAPHICAL DISCUSSION}

Abstract: The dropout rate of undergraduate students is a complex phenomenon that cannot be analyzed without taking into consideration a wider historical context for it is a consequence of previous educational levels, which influence in several different ways higher education dropout rates. School evaluation permeates all these processes and can help to identify dropout signs, reducing or even preventing it. This article analyzes the theoretical production contained in Digital Library of Thesis and Dissertations which analyzes the dropout issue and its relationship with evaluation between 2008-2009. The methodology is based on bibliographical survey denominated state of the art or state of knowledge, which contributes to the discussion and mapping out of the academic production both in terms of qualitative and quantitative analyses. We found that the relationship between dropout rates and evaluation has received little scholarly attention, being even more scarce than the studies on undergraduate studies dropout rates.

Key words: School dropout rates; Higher education; School Evaluation. 


\section{INTRODUÇÃO}

A evasão é um fenômeno social complexo, definido como interrupção no ciclo de estudos (GAIOSO, 2005). É um problema que vem preocupando as instituições de ensino em geral, sejam públicas ou particulares, pois a saída de alunos provoca graves consequências sociais, acadêmicas e econômicas. A pesquisa de Silva Filho (2007) revela que, no período compreendido entre 2000 e 2005, no conjunto formado por todas as Instituições de Ensino Superior (IES) do Brasil, a evasão média foi de $22 \%$ e atingiu $12 \%$ nas públicas e $26 \%$ nas particulares. Revelou que são poucas as instituições que possuem um programa institucional regular de combate à evasão, com planejamento de ações, acompanhamento de resultados e coleta de experiências bemsucedidas.

A fim de demonstrar a dimensão dos problemas vivenciados pelas IES, cabe mencionar que a quantidade de matrículas, em 2008, foi de 5.080.056 alunos. Considerando a média apresentada por Silva Filho (2007) de $22 \%$, cerca de 1.117.612 alunos estiveram fora do sistema de ensino superior no referido ano.

Zago (2006) apresenta outro fator a ser considerado: somente $9 \%$ dos jovens entre 18 e 24 anos frequentam o ensino superior, um dos índices mais baixos da América Latina. Conforme a autora, determinados estudos indicam que 25\% dos potenciais alunos são carentes e não têm condições de ingressar no ensino superior, ainda que este seja gratuito. $\mathrm{O}$ aumento quantitativo do número de vagas foi considerável nos últimos anos, mas a sua concentração no ensino pago, ou seja, nas escolas particulares, não reduziu as desigualdades entre os grupos sociais nas últimas décadas.

Para comprovar o quanto é grave esse número para o ensino superior brasileiro, Silva Filho e Hipólito (2009) apontam que somente 8\% da população adulta tem formação superior, enquanto outros países apresentam um percentual maior: Coreia, 32\%; Espanha, 28\%; Rússia, 55\% e Chile, 13\%, na década de 1990. Se for considerada a baixa formação superior e, ainda, incluída a questão da evasão, podemos afirmar que o problema do ensino superior é altamente relevante.

Uma questão importante apresentada por Silva Filho e outros (2007) é o fato de se minimizar frequentemente as razões da evasão, apontando em geral a falta de recursos financeiros do aluno como a principal causa para a interrupção de seus estudos. É importante que se priorize também a compreensão das questões de ordem acadêmica, como as expectativas do aluno em relação ao curso ou à instituição que podem encorajá-lo ou desestimulá-lo a priorizar a conclusão do seu curso. 
Gisi (2006) corrobora com essa análise, é difícil a permanência no ensino superior para os alunos de setores sociais menos favorecidos, não só pela falta de recursos para pagar as mensalidades, mas também pela falta de aquisição de "capital cultural" ao longo da trajetória de sua vida e de seus estudos, o que não se obtém de um momento para o outro. Essa desigualdade cultural é sentida desde a educação básica, quando a maioria dos alunos inicia seus estudos em desvantagem a outros, em virtude da ausência de oportunidades que tiveram em relação ao acesso a conhecimentos diversos, desde a mais tenra idade.

Reconhecer essas desigualdades deve ser o primeiro passo de uma escola de qualidade, caso contrário, haverá muitos alunos incluídos no sistema escolar, mas poucos irão realmente se apropriar do conhecimento que o processo de ensino e aprendizagem exige. A permanência do aluno na IES, portanto, também depende do suporte pedagógico disponibilizado por esta, no entanto encontramos muitas instituições particulares e públicas despreparadas para estes desafios.

A implementação e o acompanhamento de políticas públicas educacionais, tendo por base a igualdade de oportunidades de acesso, é uma condição necessária, mas não é a única para que ocorra a democratização efetiva nas IES particulares para combater a evasão.

As pesquisas realizadas a respeito do tema, dada a falta de consenso, apresentam várias interpretações. Silva Filho e outros (2007) destacam dois aspectos similares, mas não idênticos: a "evasão anual média", que mede a porcentagem dos alunos matriculados em um curso ou instituição, que no ano seguinte não se matricularão; e a "evasão total”, que apresenta o número de alunos matriculados que não concluíram o curso, após o seu período de oferecimento regular. Além dessas ambiguidades de interpretações, outros fatores são destacados pelos autores, como as reprovações e a tendência da taxa de evasão serem cerca de duas ou três vezes superior no primeiro ano de curso do que nos demais anos, questão que merece uma reflexão à parte mais aprofundada.

Outras pesquisas sobre evasão apresentam duas faces distintas, as quais, segundo Braga e outros (2003) são o resultado da decisão do aluno ou de uma combinação de fatores sociais, econômicos e pessoais, quer seja a necessidade precoce de ingresso do aluno no mercado de trabalho, ou as dificuldades encontradas em razão das condições desfavoráveis de currículo escolar, professores e organização da escola.

Além dos estudos mencionados, encontramos em Gaioso (2005) uma ampla reflexão sobre a evasão e suas diversas causas, a partir da visão do aluno, em pesquisa realizada em uma IES no período de 2000 a 2003. Na obra desse autor, 
são apontados problemas como a falta de orientação vocacional, imaturidade do estudante, reprovações sucessivas, dificuldades financeiras, falta de perspectiva de trabalho, ausência de laços afetivos na universidade, ingresso na faculdade por imposição familiar, casamentos não planejados e nascimento de filhos.

Lima (2008, p. 39) afirma que a "[...] associação entre fatores socioeconômicos e evasão na educação superior pode assumir níveis diferentes, a depender do fato de a pesquisa ser realizada em instituição pública ou privada".

Um importante evento realizado em Serra Negra - SP, em outubro de 1995, "VI Fórum de Pró-Reitores de Graduação", chamou a atenção para o fato de a evasão e a retenção não poderem dissociar-se do processo mais amplo da avaliação institucional, sob o risco de os indicadores parciais não contemplarem as causas mais significativas dos cursos de graduação, como as questões internas da instituição.

Isto significa que é possível desenvolver programas nas IES por meio da avaliação institucional, um importante instrumento acadêmico e de gestão, a qual envolve não somente a prestação de contas, a mensuração ou o mero controle, mas também a revisão e construção de processos de melhoria da qualidade de ensino; seus resultados podem facilitar, significativamente, todas as ações avaliativas, sendo um organizador de ideias dispersas e fragmentadas na instituição (DIAS SOBRINHO, 2003).

A avaliação institucional, por participar ativamente da vida da instituição, é detentora de uma visão privilegiada da universidade e pode contribuir, sobremaneira, com os processos acadêmicos e administrativos, sendo um importante instrumento de correção de metas e objetivos. Em relação à evasão escolar, pode antecipar procedimentos institucionais que evitem a saída dos alunos.

Os principais conceitos abordados na presente pesquisa são: evasão escolar (GAIOSO, 2005; KIRA, 1998; POLYDORO, 1995); avaliação institucional (DIAS SOBRINHO, 2008, 2003, 1995); e ensino superior (CUNHA, 2000; SGUISSARDI, 1995), os quais procuramos articulá-los historicamente e teoricamente, entendendo que o fenômeno evasão não pode ser desvinculado dessas relações. Outros fatores devem ser considerados, como o surgimento tardio do ensino superior no Brasil, as políticas sociais, as políticas públicas e compensatórias das últimas décadas, a expansão desenfreada das instituições de ensino e a implementação de programas para avaliá-las.

Para a definição da pesquisa foram utilizados alguns critérios de seleção no site da Biblioteca Digital de Teses e Dissertações (BDTD). Buscamos pelos termos correlatos à evasão escolar, como fracasso escolar e abandono de curso, sempre na área de Educação e no nível de ensino superior. Essas escolhas 
estão alinhadas com o objetivo desta pesquisa e justifica-se pela necessidade da delimitação do universo da pesquisa, uma vez que se trata de uma biblioteca digital dinâmica que recebe, diariamente, novos trabalhos. Os acessos ao citado site para a pesquisa referem-se ao mês de agosto de 2009 e tem por objetivo verificar as tendências dos estudos sobre evasão e a presença da questão da avaliação institucional na realidade de análise da evasão no ensino superior.

Para tanto, elaboramos uma desconstrução inicial das obras dos autores selecionados, com o objetivo de encontrar as categorias de análise e assim levantar as questões comuns ou não existentes entre os autores, sobre a evasão e a avaliação institucional, como meio de auxiliar as instituições a refletirem sobre estes temas, bem como sobre a desigualdade social e seus efeitos na evasão escolar.

O método de investigação utilizado neste estudo foi o da pesquisa denominada estado da arte ou estado do conhecimento, definido como sendo de caráter bibliográfico, o qual auxilia na discussão e no mapeamento da produção acadêmica sobre um determinado tema, possibilitando ao pesquisador destacar as condições que foram produzidas as teses e as dissertações. Cabe ressaltar que a pesquisa bibliográfica pertinente a este estudo visa compreender o universo de trabalhos teóricos desenvolvidos no campo da Educação (FERREIRA, 2002).

As dissertações e as teses foram separadas pela discussão dos termos: "abandono escolar" (um resultado), sobre o ensino de jovens e adultos (EJA); "fracasso escolar", 59 resultados entre teses e dissertações, sendo 52 sobre o ensino fundamental e sete sobre o ensino médio; “evasão escolar”, 26 resultados.

Como o objetivo desta pesquisa é a discussão da evasão no campo da Educação, os trabalhos encontrados foram inicialmente separados por áreas de conhecimento: administração (quatro trabalhos), direito (um trabalho), economia (três trabalhos) e psicologia (quatro trabalhos). Na área de Educação foi necessário identificar os níveis de ensino, foram localizados seis trabalhos no ensino fundamental, sete no ensino médio e quatro no ensino superior, sendo os últimos, nosso objeto de análise para o presente estudo. O corpus foi definido pelos trabalhos explicitados a seguir

"O trancamento de matrícula na trajetória acadêmica do universitário: condições de saída e de retorno à instituição" (POLYDORO, 2000). A autora tem como principal objetivo pesquisar o trancamento de matrícula e as condições envolvidas na saída e no retorno do estudante à instituição, para entender a sua trajetória acadêmica. A pesquisa foi realizada a partir da escolha de um campus de uma universidade da região de Campinas, para resguardar as características desse universo e delimitar a investigação. Os cursos escolhidos foram oferecidos 
no período de 1995 a 1999, em uma instituição privada de caráter comunitário e confessional católico.

A autora afirma que apenas uma minoria consegue se reintegrar à graduação após trancar, cancelar ou abandonar o curso. Um fator importante é que essa pesquisa foi feita em uma universidade privada, portanto, é possível supor que os motivos para a evasão sejam de ordem administrativa e financeira. Mas essa condição financeira não se justifica por si só, como já vimos anteriormente, pois de acordo com outros autores, como Gaioso (2005) e Gisi (2006), o desligamento dos cursos também ocorre nas instituições públicas, de forma indireta, como por exemplo, pela incompatibilidade entre horário de estudo e trabalho.

Nos fatores envolvidos no fenômeno "trancamento de matrícula", encontramos argumentos relacionados a aspectos levantados pelo próprio estudante e ao seu contexto de vida. Porém, no retorno, temos mais de um motivo, e todos eles envolvendo diferentes circunstâncias da vida pessoal, profissional e acadêmica do aluno.

As questões de integração acadêmica do estudante na escola também aparecem como justificativa para o trancamento de matrícula. Assim, o impacto causado pela experiência acadêmica na vida do aluno torna a IES responsável pela promoção do desenvolvimento e interação do estudante com o cotidiano do curso e com os diferentes contextos de aprendizagem.

Esta é a preocupação da reflexão realizada pelo estudo "Orientação profissional nos cursos de graduação: contribuições e limites" (SOUSA, 2005, p. 8), o objetivo é "avaliar o reflexo do SOAPPe na orientação profissional e, conseqüentemente, na adaptação ao curso freqüentado ou escolha de outro, contribuindo, dessa forma, para reduzir a evasão [...]". A pesquisa foi feita no Serviço de Orientação e Acompanhamento Psico-Pedagógico da Universidade Católica de Brasília (SOAPPe), sendo dividida em duas etapas: a primeira com o preenchimento de formulários sobre o perfil socioeconômico da família do aluno que procurou o serviço no período de 2001 a 2004; já a segunda etapa consiste na aplicação de um questionário sobre uma amostra de alunos que concluíram o programa de orientação profissional (SOUSA, 2005).

"Dialogar ou evadir: Eis a Questão! Um estudo sobre a permanência e a evasão na educação a distância" (FAVERO, 2006) aborda a questão da evasão especificamente no Ensino a Distância (EAD) sobre uma perspectiva freireana e piagetiana. Discute a importância do diálogo para a permanência do aluno no curso. O objetivo principal da pesquisa é "[...] verificar se o estabelecimento do diálogo entre os alunos em curso, na modalidade a distância, influencia na 
permanência dos alunos no curso escolhido" (p. 18). A pesquisa baseou-se em um curso ministrado a professores da Educação Profissional das Escolas Técnicas do Rio Grande do Sul, denominado "Capacitação em Ambiente Virtual para EAD”. Foi promovido pela Escola Técnica da Universidade Federal do Rio Grande do Sul (UFRGS), Núcleo de Educação a Distância do Centro Federal de Educação Tecnológica (CEFET) de Pelotas e pelo Núcleo de Multimídia e Ensino a Distância da Escola de Engenharia da UFRGS (FAVERO, 2006).

"Efeitos da Política de Cotas na Universidade de Brasília: uma análise do rendimento e da evasão" (CARDOSO, 2008) tem como objeto de estudo o sistema de cotas da Universidade de Brasília (UnB), que foi instituído em 2003. Esse plano busca a integração social, étnica e racial por meio de reserva de vagas para negros e indígenas (cotistas), o incentivo à permanência destes no ensino e um programa de apoio ao ensino público do Distrito Federal. O objetivo da pesquisa é analisar a demanda de candidatos cotistas e não cotistas da UNB, caracterizar e analisar o desempenho e o rendimento dos dois grupos nos cursos em que foram aprovados e, ainda, levantar a evasão desse universo. As informações provêm de bancos de dados da UNB, do processo seletivo e do rendimento acadêmico relativo ao segundo semestre de 2004 a 2006 . O estudo apresenta dois objetos de análise distintos: os candidatos aprovados no vestibular de 2006 e os ingressantes no segundo semestre de 2004 e de 2005 (CARDOSO, 2008).

Vale destacar a análise que a autora apresenta sobre a evasão dos estudantes cotistas na UnB, partindo do pressuposto que o abandono está associado à renda familiar e ao rendimento acadêmico. Nesse sentido, a evasão seria maior no universo dos alunos cotistas do que no dos não cotistas, mas Cardoso (2008) evidencia que, em outros trabalhos relacionados à evasão no ensino superior, a questão financeira, ou o desempenho acadêmico, contribuem muito pouco na decisão do aluno em evadir-se. Apresenta várias questões apontadas por outros autores como: falta de identidade com o curso; escolha errada da carreira; desencanto com a universidade; baixa demanda pelo curso, possivelmente associada ao baixo prestígio social do curso escolhido, entre eles, as licenciaturas.

Como vimos, o fenômeno da evasão no ensino superior não pode ser analisado isoladamente, é preciso reconhecê-lo em todos os níveis de ensino. A necessidade de um capital cultural marca a evasão nos diversos sistemas educacionais. A conclusão de um curso superior é influenciando igualmente por esse processo; a desigualdade social existente afeta diretamente os setores de menor poder aquisitivo e é motivo de preocupação constante dos sistemas de ensino públicos e privados. Diante dessa realidade, procuramos destacar 
autores que pensam a evasão no decorrer da trajetória acadêmica do aluno, como o estudo apresentado por Freitas (2002), que trata da exclusão do aluno ainda no ensino fundamental, ou por Alonso (2009), que aborda a questão da desigualdade social como um dos fatores responsáveis pela saída de alunos dos bancos escolares no ensino fundamental.

Diversos conceitos sobre a evasão foram encontrados, como por exemplo o definido por Gaioso (2005) como sendo a interrupção no ciclo de estudos, ou por Kira (1998) como a fuga de alunos, e outras definições mais complexas apresentadas por Polydoro (2000) e Cardoso (2008) com a identificação de mais de uma forma de evasão na escola. Temos ainda uma diversidade de fatores para a evasão escolar que resultam de vários processos sociais e culturais desde a criação da instituição escola.

\section{A EVASÃO E A AVALIAÇÃO INSTITUCIONAL NO ENSINO SUPERIOR}

Procuramos pensar a avaliação institucional como um instrumento para reflexão sobre a evasão escolar no ensino superior, pois ela ocorre dentro das IES, com a comunidade acadêmica no trabalho docente, na gestão das instituições e na definição curricular.

A educação superior tem atividades complexas, relacionadas com valores éticos, epistêmicos, políticos, sociais, econômicos e culturais. Nas últimas décadas estamos sob influência do 'Estado avaliador', que organiza a avaliação muito mais como instrumento de regulação, o que extrapola sua dimensão burocrática-legalista de controle, modelação, ajustamento e fiscalização. Marcada por um conjunto de processos e relações produzidas em seu cotidiano dinâmico e processual, auxilia a compreender o caráter "institucional" da avaliação (DIAS SOBRINHO, 2003; 2008).

Esse processo, além de funções avaliativas pontuais e fragmentadas, procura entender a universidade como um todo, pela busca da compreensão do conjunto de suas dimensões (DIAS SOBRINHO, 1995). Para isso, precisa contar com a participação da comunidade acadêmica da IES, reconhecer que se trata de um processo normalmente carregado de significados e, portanto, permeado, em diversas ocasiões, de tensões e conflitos. Toda essa complexidade que a envolve não pode ser considerada como um problema, mas como desafios carregados de exigências técnicas, éticas e políticas específicas de sua área.

Essa abrangência institucional produz informações que podem auxiliar na consolidação do ensino, na revisão dos seus processos e na solução de proble- 
mas, por exemplo, a evasão escolar, que traz prejuízos sociais e acadêmicos tanto para as instituições de ensino quanto para a sociedade. Essa realidade expõe uma das fragilidades do sistema educacional brasileiro pelo fato de não conseguir manter o aluno em sala de aula.

De acordo com Pereira (2003), o estudo da evasão está associado à discussão da qualidade de ensino, destacando que esta provoca, em alguns casos, a perda definitiva do aluno. Para que haja avanço, o autor propõe a avaliação institucional, mas adverte que essa atividade ainda está muito associada aos campos de currículos dos cursos e do desempenho dos docentes e discentes. Isso significa que existem poucas articulações pensadas entre avaliação institucional, evasão e qualidade de ensino. Cabe mencionar ainda que o estudo da evasão é um campo vasto e complexo, o qual envolve questões pedagógicas, psicológicas, sociais, políticas, econômicas, administrativas, entre outras.

A evasão no ensino superior já vinha sendo tema de diversos estudos isolados [...] como os trabalhos de Rosa (1977), Costa (1979), Maia (1984), Moysés (1985), Hamburger (1986), entre outros. Segundo Braga, Miranda-Pinto e Cardeal (1996), esse tema configurava-se como preocupação das universidades públicas e do MEC desde 1972. (POLYDORO, 2000, p. 45)

Um dos debates precursores no Brasil sobre evasão em IES emergiu dentro de um processo de discussão de avaliação institucional. Trata-se dos indicadores do Programa de Avaliação Institucional das Universidades Brasileiras (PAIUB), realizados por diferentes IES, especificamente as públicas. O seu marco formal se deu em fevereiro de 1995, com a realização do Seminário sobre Evasão nas Universidades Públicas Brasileiras, promovido pela Secretaria de Educação Superior (SESu) e Ministério da Educação (MEC). A fim de encontrar um conceito comum e analisar o fenômeno da evasão, foi criada a "Comissão Especial de Estudo sobre Evasão" a partir de uma metodologia única a ser utilizada pela IES, na busca de propostas para a diminuição dos índices de evasão observados (POLYDORO, 2000).

Outro evento foi realizado em Serra Negra (SP), em outubro de 1995, o "VI Fórum de Pró-Reitores de Graduação". Chamou a atenção para o fato de a evasão e a retenção não poderem estar dissociadas do processo mais amplo da avaliação institucional, sob o risco dos indicadores não contemplarem as causas mais significativas do abandono dos cursos de graduação, como as questões internas da instituição. Mas essa foi uma experiência que parece ter perdido continuidade, predominando estudos dispersos. 
Podemos perceber que o termo evasão não apresenta os mesmos critérios de aferição de abandono do ensino superior (CARDOSO, 2008; POLYDORO, 2000). Partindo do pressuposto que cada IES tem seus critérios para aferir a evasão de seus alunos e que, dentro do sistema educacional as transferências entre instituições não são rastreáveis, a coleta de dados para fins de comparação entre as IES fica comprometida.

Para indicar a complexidade dessas questões, apresentamos as sistematizações da Comissão Especial da Evasão (MEC, 1996 apud POLYDORO, 2000), segundo as quais há distinção entre evasão de curso - saída do curso sem conclúi-lo e a evasão do sistema - abandono do aluno do ensino superior. Cardoso (2008), por sua vez, apresenta a "evasão aparente" e a "evasão real", sendo a primeira a mobilidade de um curso para outro, e a segunda, a desistência do aluno em cursar a educação superior.

Silva Filho (2007) define dois aspectos similares, mas não idênticos: evasão anual, que verifica a diferença entre alunos matriculados de um ano para o outro, e a evasão total, ao comparar o número de alunos matriculados com o número final de alunos concluintes do curso.

As pesquisas realizadas sobre evasão indicam a necessidade de mais diálogos que dêem início a um debate sobre a sua complexidade no espaço educacional, para facilitar a comparação entre as IES. Nesse sentido, a pesquisa de Polydoro (2000) pode ser considerada um marco, pois se tornou uma das referências mais citadas na maioria dos estudos sobre evasão. A autora identifica em seu estudo de caso o percurso dos alunos pelos semestres e apresenta as tendências em relação ao trancamento de curso, uma modalidade de evasão temporária com fortes tendências à evasão definitiva dentro do ambiente educacional pesquisado.

Encontramos em nossa pesquisa bibliográfica uma diversidade de objetivos nas análises e discussões sobre a evasão. Assim, temos pesquisas com foco em determinados cursos por modalidade de oferecimento, por exemplo, o EAD, ou por turno, por região, por instituição, etc., o que representa um viés diferente para cada objetivo da pesquisa, em geral de estudos de casos.

Com relação ao levantamento de dados oficiais sobre o fenômeno da evasão, o site do Instituto Nacional de Estudos e Pesquisas Educacionais Anísio Teixeira (INEP) não disponibiliza de forma explícita os números sobre a saída de alunos; o cálculo pode ser aproximado quando se leva em conta o número de alunos matriculados, ingressantes e concluintes a cada ano. Essa prática revela-se diferente do que é feito em relação ao aumento do número de alunos com acesso ao ensino superior, que vem sendo largamente divulgado pelos órgãos governamentais. A falta de detalhes sobre os números encontrados causa problemas, pois não temos como qualificá-los, ou seja, não há o ras- 
treamento do movimento do aluno dentro do sistema educacional e, assim, a evasão em uma instituição pode representar matrícula em outra. Os diversos conceitos existentes para evasão não podem ser identificados nos dados do Inep; isso se dá mais por meio das pesquisas acadêmicas dentro das diversas áreas do ensino.

A disponibilidade de dados oficiais pelo governo deveria ser feita de forma mais direta e objetiva para que pudéssemos ter acesso e entender os números que viriam de fato a quantificar e qualificar a evasão. Isto possibilitaria um avanço em alterações nas políticas públicas que auxiliasse os estudantes e as instituições públicas ou particulares no combate à evasão escolar.

A avaliação institucional, por sua vez, segundo Dias Sobrinho (1995, p. 55), “[...] ultrapassa largamente a mera medição ou quantificação e se esforça para compreender os significados das redes de relações cuja tessitura constrói a universidade". Mas essa avaliação, para se tornar uma aliada importante no combate à evasão na universidade, depende em grande medida da explicitação concreta de dados oficiais mais elaborados. Dessa forma, poderia colaborar para minimizar os efeitos da evasão e se tornar em mais um dos meios de mudança da cultura acadêmica, seja no trabalho docente, na gestão das instituições, nas redefinições curriculares, entre outras dimensões da estrutura do ensino superior.

Isoladamente, algumas instituições nacionais, públicas e privadas, vêm procurando apurar o número de estudantes que evadem e, para isso, desenvolvem programas que buscam averiguar os motivos da saída, procurando meios para manter os alunos em seus cursos. De acordo com Polydoro (2000), isso é possível por intermédio de ações que controlem os fatores que levam à evasão, bem como sua prevenção, com estratégias coordenadas e de avaliação de programas.

A efetivação desses programas só é possível por meio da avaliação institucional e definir como princípio uma compreensão crítica e integrada dos processos pedagógicos e de socialização que existem na universidade, cujo objetivo é a promoção contínua da qualidade do ensino. Devemos buscar o entendimento entre as partes e de modo articulado entender a globalidade da instituição, por meio de um esforço metodológico. Assim, a partir das questões levantadas na avaliação institucional, teríamos uma base para diferentes ações de melhoria da realidade educacional em foco (DIAS SOBRINHO, 1995).

A compreensão global da avaliação institucional consegue identificar os elementos que conduzem o aluno à evasão escolar ou as questões de deficiência da educação básica, segundo Gaioso (2005). Ou ainda, conforme Polydoro (2000) consegue explicitar vários aspectos ligados ao cotidiano do aluno e do curso e, portanto, identifica as variáveis socioculturais que atuam em conjunto nos processos de evasão. 
A autoavaliação das IES como um processo permanente de reflexão sobre todas as ações institucionais, como estrutura, atividades de ensino, pesquisa, extensão, relações externas e internas, associadas às atividades administrativas, produz conteúdos necessários para orientar a gestão da direção institucional, indo além da prestação de contas ao MEC. A articulação entre avaliação e gestão pode ser compreendida de formas diferentes, pois depende da missão, das razões históricas e das características de cada uma das IES. O caminho do conhecimento institucional e de seus problemas internos está em programas que proponham mudanças que possam reverter, entre outras medidas, o elevado número de alunos evadidos.

Segundo Polydoro (2000), os estudos realizados pelos autores têm demonstrado a existência de diferentes enfoques sobre a avaliação do ensino superior, considerando a complexidade, amplitude e caráter interdisciplinar da avaliação. Por um lado, existe uma demanda de aumento da produtividade e de controle exercido pela regulação do Estado e, por outro, de autoconhecimento necessário para a melhoria da qualidade institucional das IES.

Para Worthen, Sander e Fitzpatrick (2004), a avaliação deve ser utilizada como veículo de identificação, esclarecimento e aplicação de critérios defensáveis para determinar valores, a qualidade, a utilidade e a importância do objeto avaliado. A avaliação institucional não é uma invenção dos educadores; segundo Sander (2008), foi criada no contexto mais amplo das Ciências Sociais Aplicadas para o mundo dos negócios ou para o setor público, por meio de teóricos de administração e da gestão do desenvolvimento institucional. A avaliação institucional impôs-se como meio para medir a eficiência, a eficácia e a produtividade na administração e na gestão da educação.

Sander (2008) afirma ainda que a experiência das universidades brasileiras na área da avaliação institucional remonta à década de 1970, época em que os processos avaliativos e sistemáticos realizados pela Coordenação de Aperfeiçoamento de Pessoal de Nível Superior (CAPES) eram voltados para os programas de pós-graduação. O autor afirma que a preocupação do Estado avaliativo, baseado em políticas neoliberais sobre as instituições universitárias provocou uma reação contra as exigências do MEC e, em 1993, foi criada a Comissão Nacional de Avaliação, representada pelos reitores das universidades brasileiras. Nesse contexto, os dirigentes elaboraram um conjunto de propostas que deram origem ao PAIUB, reconhecido pelo MEC e aceito pela comunidade acadêmica como meio de promover o desenvolvimento institucional das universidades brasileiras. Naquele momento, esse projeto, de natureza emancipatória e participativa, combinou práticas de autoavaliação e de avaliação externa. 
Apesar da proposta do PAIUB, a comunidade acadêmica foi surpreendida pela Medida Provisória $n^{\circ} 1.018$, de 8/6/1995, que instituiu o exame denominado Provão, de natureza quantitativa e uniforme, com critérios internacionais e práticas que estimularam comparações entre desiguais “[...] muitas vezes baseados em dados desprovidos de validade técnica, sentido pedagógico e solidariedade humana" (SANDER, 2008, p. 14).

Atualmente, a avaliação institucional está amparada na Lei $n^{\circ} .10 .861$, de 14/4/2004, que instituiu o Sistema Nacional de Avaliação da Educação Superior (SINAES).

Conforme disposto no artigo $1^{\circ}$. da lei, o objetivo do SINAES é assegurar o processo nacional de avaliação das instituições de educação superior, com a finalidade de promover a melhoria da qualidade do ensino superior, orientar a expansão de sua oferta, aumentar sua eficácia institucional e efetividade acadêmica e social e, especialmente, promover o aprofundamento dos compromissos e responsabilidades sociais das instituições de educação superior, por meio da valorização de sua missão pública, da promoção dos valores democráticos, do respeito à diferença e à diversidade, da afirmação da autonomia e da identidade institucional. (SANDER, 2008, p. 15)

A avaliação não pode ser resumida como atividade de coleta e divulgação de dados, como se esse procedimento provocasse as transformações necessárias para a melhoria da qualidade educacional. Deve ser entendida como um dos meios de viabilização de mudanças na cultura acadêmica, no trabalho docente, na gestão das instituições, nas definições curriculares e, acima de tudo, na estruturação da educação superior.

Marback Neto (2007) apresenta dois tipos de avaliação na universidade: ensino-aprendizagem e questões da avaliação institucional. O autor compreende a avaliação como um instrumento de gestão universitária, pelo qual, de acordo com a Lei de Diretrizes e Bases da Educação Nacional (LDB), as universidades brasileiras podem escolher uma estrutura em função de sua cultura e especificidade, o que lhe permite flexibilidade de acordo com a abordagem administrativa, dependendo do seu tamanho e meio ambiente. A dificuldade está na decisão bipartida entre as áreas administrativa e acadêmica, nas quais os objetivos gerenciais conflitam com os acadêmicos e fazem da avaliação um instrumento de controle coletivo, com diagnóstico complexo e de difícil implementação de seus resultados. As críticas da comunidade acadêmica aos critérios adotados referem-se ao caráter fiscalizador e não participativo realizado com os gestores dos cursos. Outro fator que gera problema é a questão da qualidade educacional, pela dificuldade na definição de parâmetros. 
Para Marback Neto (2007), como para outros autores mencionados, o processo de avaliação institucional deve ter como ponto máximo a autoavaliação, com destaque ao princípio crítico-transformador e não ao tecnoburocrático. É um momento coletivo de conhecimento e de busca de soluções dos problemas da universidade, juntamente com o processo democrático das diversas instâncias da instituição.

Por outro lado, a avaliação externa tenciona um de seus problemas principais, que se refere às comissões de especialistas formados por quase $95 \%$ de membros vinculados às universidades públicas. A questão é que essas comissões exigem das IES particulares as mesmas condições de funcionamento das IES públicas, desconsiderando as diferenças culturais e especificidades de gestão existentes. Outro ponto importante dos processos regulatórios das IES pelo Estado é o Plano de Desenvolvimento Institucional (PDI) e a publicação da citada Lei do SINAES, que dispõe sobre como as IES devem ser examinadas, indicando dez dimensões de avaliação (MARBACK NETO, 2007).

Para demonstrar suas críticas à homogeneização das IES pela avaliação, Marback Neto (2007) comparou duas universidades, uma particular, na região Sudeste, e outra pública, no Nordeste, examinando toda a questão de estrutura organizacional, modelo de decisão, planejamento, cultura organizacional e sistemas de comunicação internos de cada uma.

Nas duas universidades pesquisadas, em função das características de cada gestão e das resistências encontradas, o autor revela que a avaliação institucional não integra a rotina das mesmas; as dificuldades existentes ocorrem em virtude do excesso de centralização, lentidão na gestão, e ainda o medo do professor em ser punido ou exposto pela publicação da avaliação. Em ambas as instituições, os gestores não informam como irão direcionar os resultados da avaliação institucional, sendo essa atitude um sério problema, pois a ausência de um sistema democrático de funcionamento das IES constitui-se em um grande obstáculo à implantação de uma cultura avaliativa participativa.

$\mathrm{O}$ autor conclui que os objetivos seculares da universidade não mudaram tanto, mas a organização sim, modificando-se constantemente. À medida que as transformações econômicas, políticas e sociais, ocorridas no modo de vida da população, tornam-se mais rápidas, a mesma exigência de transformação e agilidade vem sendo imposta à universidade. As funções de ensino, pesquisa e extensão pertencem a todos, além do fato de ter que prestar contas de suas atividades à comunidade, seja em uma IES pública ou particular (MARBACK NETO, 2005). 
Quanto à vinculação entre a autoavaliação e a gestão, buscamos subsídio nos resultados da pesquisa interinstitucional Avaliação da educação superior no Brasil: desenvolvimento institucional e qualidade do trabalho acadêmico em questão, desenvolvida no período 2006-2008 pelo Programa de Pesquisa da Associação Nacional de Política e Administração da Educação (ANPAE), subprojeto: Avaliação institucional: projetos de auto-avaliação e vinculação entre avaliação, gestão e financiamento. Nessa pesquisa, foram analisados documentos de 14 universidades federais, cerca de mais de 30\% das instituições existentes em 2006 (SANTOS, 2008).

Esse estudo dividiu-se nos seguintes tópicos: concepções de universidade; finalidade da avaliação; padrões de avaliação; concepção da Comissão Própria de Avaliação (CPA); instrumentos e formas de coleta de dados previstas; autonomia das propostas em relação ao roteiro do SINAES; operacionalização da autoavaliação; vinculação entre avaliação e gestão; e vinculação entre avaliação e financiamento.

A pesquisa considerou a concepção de universidade por entender que um processo autoavaliativo depende do que as instituições conhecem de si próprias; do envolvimento delas com a sociedade, pois tendem a se conceberem como participantes dos problemas locais e do processo de desenvolvimento regional como forma de legitimar a existência institucional (OLIVEIRA et al, 2008).

O estudo de Oliveira e outros (2008) apresenta IES que adotam um modelo mais participativo, de cunho diagnóstico e formativo, devido ao seu histórico de lutas, e outras de caráter mais gerencialista, de modo que a gestão estratégica de ambas auxilie na tomada de decisão nos diferentes espaços da instituição, tornando-os mais racionais, eficientes e eficazes. De forma geral, parece haver uma tendência em uma mescla de dois modelos: o participativo e o gerencial. Os autores reforçam que, pelo fato de o processo de avaliação ser relativamente recente, ainda não é possível uma caracterização no que se refere à constituição de modelos. Além disso, existe ainda a diferença entre universidades privadas e públicas.

Nas IES privadas, muitas vezes a avaliação é feita em gabinetes ou por especialistas contratados para este fim. Nas universidades públicas, especialmente as de grande porte, já existe um processo contínuo de avaliação, embora esse processo não fosse compreendido como avaliação institucional. Em diferentes espaços da instituição - conselhos, unidades, programas de pós-graduação e cursos de graduação, departamentos, dentre outros - avaliam-se permanentemente as atividades, ainda que essas atividades não sejam registradas ou sistematizadas como avaliação. (OLIVEIRA et al, 2008, p. 44) 
A vinculação entre avaliação e gestão aparece explicitamente em todos os projetos de avaliação analisados; as instituições demonstram a intenção de utilizar os dados para aperfeiçoar a gestão por meio de seu planejamento estratégico, principalmente os de caráter administrativo, impactando, portanto, diretamente na tomada de decisão dentro das IES. Os autores ainda evidenciam que é prematuro conceber que os resultados trarão a melhoria da qualidade da gestão e do trabalho acadêmico, mas indicam que somente a contínua autoavaliação poderá auxiliar a instituição na busca pela sua qualidade (OLIVEIRA et al, 2008).

Polydoro (1995) e Silva Filho (2007) enfatizam que, dentre tantas questões apresentadas pela avaliação institucional, a evasão escolar é uma das que deveria ser destacada pelo fato de acumular prejuízos sociais, acadêmicos e econômicos às instituições de ensino, pois sua ocorrência interfere na eficiência do sistema educacional, demonstrando as suas fragilidades.

Muitos dos motivos que levam o aluno a interromper seu curso estão explicitados na avaliação institucional, tais como: a questão da falta de capital cultural (GISI, 2006); mudanças no projeto de vida e na tomada de decisão do aluno (POLYDORO, 1995); desencantamento com o curso escolhido (KIRA, 1998). Essas questões aparecem no processo da autoavaliação, as quais devem fazer parte das medidas tomadas pelos gestores para corrigir o rumo da instituição e elevar a qualidade de ensino pretendida.

\section{CONSIDERAÇÕES FINAIS}

Realizamos esta pesquisa (2008-2009) para verificar os vários sentidos do conceito de evasão, a relação com questões de desigualdade social e saber até que ponto as discussões sobre a evasão escolar e a avaliação institucional estariam associadas e ocorrendo na área de Educação na Biblioteca Digital de Teses e Dissertações (BDTD).

Podemos dizer que a relação entre a evasão e a avaliação institucional é ainda pouco estudada. Nos trabalhos analisados, a discussão da avaliação institucional aparece de algum modo como instrumento de auxílio para a redução da evasão, mas é uma discussão secundária, mais restrita ainda que a própria discussão de evasão no ensino superior.

A evasão em sentido amplo é tratada pelos autores como a saída do aluno da instituição antes da conclusão do seu curso. As distinções entre os estudos de casos encontrados ocorrem em relação ao objeto de estudo, à teoria, ao método para identificação da evasão e aos resultados das pesquisas realizadas. 
Percebemos que a evasão tem múltiplas razões, dependendo do contexto social, cultural, político e econômico em que a instituição está inserida. Pode estar relacionada, por exemplo, diretamente à má qualidade de ensino oferecida pelas IES, provocando a perda definitiva do aluno. Para que hajam mudanças substantivas nesse processo, seria preciso desenvolver uma reflexão mais sistemática sobre a relação entre a avaliação institucional e a evasão, e seus vários significados, para ampliar um caminho de propostas e projetos de combate ao abandono escolar do aluno devido às desigualdades sociais quanto à conclusão do ensino superior. Esse caminho contribuiria qualitativamente para consolidar as atividades de ensino associadas ao campo de currículos dos cursos e de desempenho de docentes e discentes.

Portanto, o presente estudo aponta para a necessidade de se fortalecer as articulações entre avaliação institucional, evasão e qualidade de ensino, no sentido de haver uma maior explicitação e visibilidade do problema 'evasão' no ensino superior, seja público ou privado, tanto em relação às discussões acadêmicas como em relação às instituições responsáveis pelas políticas públicas educacionais. Poderíamos utilizar, por exemplo, os dados já disponibilizados anualmente pelo Instituto Nacional de Estudos e Pesquisas Anísio Teixeira (INEP) sobre o Censo da Educação Superior, que deveria agregar e disponibilizar informações detalhadas sobre a situação da evasão no país, o que auxiliaria sem dúvida a busca por soluções para este difícil problema que as IES enfrentam a cada ano.

\section{REFERÊNCIAS}

ALONSO, Rafael Feito. Êxito escolar para todos. Revista Iberoamericana de Educacion, Madrid, n. 50, p. 173-195, 2009.

BRAGA, Mauro Mendes; PEIXOTO, Maria do Carmo L.; BOGUTCHI, Tânia F. A evasão no ensino superior brasileiro: o caso da UFMG.

Avaliação, Campinas, v. 8, n. 1, p. 161-189, 2003.

CARDOSO, Claudete Batista. Efeitos da política de cotas na Universidade de Brasília: uma análise do rendimento e da evasão. 2008. 123 p.

Dissertação (Mestrado em Educação) - Universidade de Brasília, Brasília, 2008. 
CUNHA, Luiz Antonio. Ensino superior e universidade no Brasil. In: TEIXEIRA, E. M. et al. 500 anos de educação no Brasil. 2. ed. Belo Horizonte: Autêntica, 2000.

DIAS SOBRINHO, José. Avaliação educativa: produção de sentidos com valor de formação. Avaliação, Campinas, Sorocaba, v. 13, n. 13, p 193-207, mar. 2008.

DIAS SOBRINHO, José. Avaliação da Educação Superior Regulação e emancipação. In: DIAS SOBRINHO, José; RISTOFF D. I. Avaliação e compromisso público: a educação superior em debate. Florianópolis: Insular, 2003. p. 35-52.

DIAS SOBRINHO, José. Universidade: processos de socialização e processos pedagógicos. In: DIAS SOBRINHO, J.; BALZAN, N. C. Avaliação Institucional: teorias e experiências. São Paulo: Cortez, 1995. p. 15-16.

FAVERO, Rute Vera Maria. Dialogar ou evadir: Eis a questão! Um estudo sobre a permanência e a evasão na Educação a Distância. 2006. 167 p. Dissertação (Mestrado em Educação) - Universidade Federal do Rio Grande do Sul, Porto Alegre, 2006.

FERREIRA, Norma Sandra de Almeida. As pesquisas denominadas "Estado da Arte”. Educação \& Sociedade, Campinas, v. 23, n. 79, p. 257-272, ago. 2002.

FREITAS, Luiz Carlos. A internalização da exclusão. Educação e Sociedade, Campinas, v. 23, n. 80, p. 299-325, set. 2002.

GAIOSO, Natalicia Pacheco de Lacerda. O fenômeno da evasão escolar na educação superior no Brasil. 2005. 75 f. Dissertação (Mestrado em Educação) - Programa de Pós-Graduação em Educação da Universidade Católica de Brasília, Brasília, 2005.

GISI, Maria Lourdes. A Educação Superior no Brasil e o caráter de desigualdade do acesso e da permanência. Diálogo Educacional, Curitiba, v. 6, n. 17, p. 97-112, 2006.

KIRA, Luci Frare. A evasão no ensino superior: o caso do curso de pedagogia da Universidade Estadual de Maringá (1992-1996). 1998. 106 f. Dissertação (Mestrado em Educação) - Programa de Pós-graduação em Educação da Universidade Metodista de Piracicaba, Piracicaba, 1998. 
LIMA, João Batista Gomes de. Estudo da evasão escolar do ponto de vista econômico: o caso dos Centros universitários Camilianos do Brasil. 2008. 86 f. Dissertação (Mestrado em Ciências Contábeis) - Programa de Pós-graduação em Ciências Contábeis da Fundação Instituto Capixaba de Pesquisa em Contabilidade, Economia e Finanças, Vitória, 2008.

MARBACK NETO, Guilherme. A gestão do ensino superior em xeque. Diálogo Educacional, Curitiba, v. 5, n. 16, p. 281-292, 2005. Avaliação: instrumento de gestão universitária. Vila Velha: Hoper, 2007.

OLIVEIRA, João Ferreira et al. Avaliação institucional: projetos de auto-avaliação e vinculação entre avaliação, gestão e financiamento. In:

OLIVEIRA, J. F.; FONSECA, M. Avaliação institucional: sinais e práticas. São Paulo: Xamã, 2008. p. 37-53.

PEREIRA, Fernanda Cristina Barbosa. Determinantes da evasão de alunos e os custos ocultos para as instituições de ensino superior: uma aplicação na universidade do extremo sul catarinense. 2003. 172 f. Tese (Doutorado em Engenharia de Produção) - Programa de Pós-graduação em Engenharia de Produção. Universidade Federal de Santa Catarina, Florianópolis, 2003.

POLYDORO, Soely Aparecida Jorge. Evasão em uma instituição de ensino superior: desafios para a psicologia escolar. 1995. 145 p. Dissertação (Mestrado em Psicologia) - Departamento de Pós-Graduação em Psicologia da Pontifícia Universidade Católica de Campinas, Campinas, 1995.

\section{O trancamento de matrícula na trajetória acadêmica no}

universitário: condições de saída e de retorno à instituição. 2000. 167 p. Tese (Doutorado em Educação) - Universidade Estadual de Campinas, Campinas, 2000.

SANDER, Benno. Avaliação institucional em construção. In: OLIVEIRA, J. F.; FONSECA, M. Avaliação institucional: sinais e práticas. São Paulo: Xamã, 2008.

SANTOS, Jocyléia Santana. Apresentação. In: OLIVEIRA, J.F.; FONSECA, M. Avaliação institucional: sinais e práticas. São Paulo: Xamã, 2008.

SGUISSARDI, Valdemar. Para avaliar propostas de Avaliação do Ensino Superior. Revista Brasileira de Estudos Pedagógicos, Brasília, v. 76, n. 184, p. 549-578, set./dez. 1995. 
SILVA FILHO, Roberto Leal Lobo et al. A evasão no ensino superior brasileiro. Cadernos de Pesquisa, São Paulo, v. 37, n. 132, p. 641-659, 2007.

SILVA FILHO, Roberto Leal Lobo; HIPÓLITO, Oscar. Financiamento e expansão do ensino superior. Disponível em: http://www.jornaldaciência. org.br/Detalhe.jsp?id=62770. Acesso em: 16 abr. 2009.

SOUSA, Elizene Maria Caliman. Orientação profissional nos cursos de graduação: contribuições e limites. 2005. 68 p. Dissertação (Mestrado em Educação) - Universidade Católica de Brasília, Brasília, 2005.

WORTHEN, Blaine R.; SANDER. James R.; FITZPATRICK, J. L.

Avaliação de programas: concepções e práticas. São Paulo: Gente, 2004.

ZAGO, Nadir. Do acesso a permanência no ensino superior: percursos de estudantes universitários de camadas populares. Revista Brasileira de Educação, Rio de Janeiro, v. 11, n. 32, p. 226-237, 2006. 